\title{
Prevention and treatment of sepsis-induced acute kidney injury: an update
}

\author{
Patrick M. Honore ${ }^{1 *}$, Rita Jacobs', Inne Hendrickx', Sean M. Bagshaw², Olivier Joannes-Boyau ${ }^{3}$, Willem Boer ${ }^{4}$, \\ Elisabeth De Waele ${ }^{1}$, Viola Van Gorp ${ }^{1}$ and Herbert D. Spapen ${ }^{1}$
}

\begin{abstract}
Sepsis-induced acute kidney injury (SAKI) remains an important challenge in critical care medicine. We reviewed current available evidence on prevention and treatment of SAKI with focus on some recent advances and developments. Prevention of SAKI starts with early and ample fluid resuscitation preferentially with crystalloid solutions. Balanced crystalloids have no proven superior benefit. Renal function can be evaluated by measuring lactate clearance rate, renal Doppler, or central venous oxygenation monitoring. Assuring sufficiently high central venous oxygenation most optimally prevents SAKI, especially in the post-operative setting, whereas lactate clearance better assesses mortality risk when SAKI is present. Although the adverse effects of an excessive "kidney afterload" are increasingly recognized, there is actually no consensus regarding an optimal central venous pressure. Noradrenaline is the vasopressor of choice for preventing SAKI. Intra-abdominal hypertension, a potent trigger of AKI in post-operative and trauma patients, should not be neglected in sepsis. Early renal replacement therapy (RRT) is recommended in fluid-overloaded patients' refractory to diuretics but compelling evidence about its usefulness is still lacking. Continuous RRT (CRRT) is advocated, though not sustained by convincing data, as the preferred modality in hemodynamically unstable SAKI. Diuretics should be avoided in the absence of hypervolemia. Antimicrobial dosing during CRRT needs to be thoroughly reconsidered to assure adequate infection control.
\end{abstract}

Keywords: Sepsis, Acute kidney injury, Septic acute kidney injury, Prevention, Treatment, Review

\section{Background}

Both sepsis and acute kidney injury (AKI) are diseases of major concern in critically ill patients. Severe sepsis is often complicated by AKI [1-4]. The overall incidence of septic AKI (SAKI) among all intensive care unit (ICU) admissions ranges between 15 and $20 \%$ [2]. Large studies in critically ill patients convincingly demonstrated the "intimate" bond between AKI and sepsis. For instance, the BEST Kidney and FINNAKI studies, which covered different time periods, both reported AKI in up to half of the septic patients [3, 4]. In a large analysis of 14,039 SAKI patients from ICUs in Australia and New Zealand,

\footnotetext{
*Correspondence: Patrick.Honore@az.vub.ac.be

${ }^{1}$ Intensive Care Department, Universitair Ziekenhuis Brussel, Vrije

Universiteit Brussel, Laarbeeklaan 101, 1090 Brussels, Belgium

Full list of author information is available at the end of the article
}

the proportions of patients stratified for risk, injury, and failure according to the RIFLE criteria were 38.5, 38.8, and $22.7 \%$, respectively [1]. Medical admissions necessitating mechanical ventilation and/or with a long ICU stay were at the highest risk. SAKI highly determines ICU outcome [1]. The BEST Kidney investigators reported a $70 \%$ overall hospital mortality in patients with SAKI [3]. Prognosis worsened with increasing age and severity of illness, use of vasoactive drugs, and mechanical ventilation [3]. In contrast, an Indian study reported an overall mortality of $52 \%$ which was directly correlated with age, disease severity, and degree of non-renal organ failure [5]. The recent IVOIRE study showed a similar mortality of around $50 \%$ at 90 days in SAKI patients with a cardiovascular SOFA score of 3-4 and under CRRT [6]. This apparent decrease of mortality over time probably implies a more adequate management of SAKI [7]. 
We review some important developments in prevention and treatment of SAKI which have contributed to this improved prognosis or hold promise for further amelioration.

\section{Pathophysiology of SAKI}

The pathophysiology of SAKI is much more complex than previously anticipated [8]. Primary conditions associated with AKI, such as sepsis, major surgery, heart failure, and hypovolemia, may all be complicated by shock. Thus, it is tempting to attribute AKI to ischemia and systemic hemodynamic changes [9]. However, renal dysfunction does not result from hypoperfusion alone but may emanate to a large extent from renal inflammation and tubular responses to various sepsis mediators. In many patients, AKI occurs without overt signs of global renal hypoperfusion and SAKI has been described in the presence of normal or even increased renal blood flow [9]. This explains why the sole correction of hemodynamic parameters often fails to prevent SAKI $[8,9]$. Taken together, the pathophysiology of SAKI is no longer based on an ischemia/reperfusion paradigm but rather embraces an aggregate of inflammation, microcirculatory dysfunction, perfusion deficit, bio-energetic reactions, and tubular cell adaptation to injury [9]. It must be admitted, however, that an intrinsic role of these pathophysiological "subsets" underlying SAKI has been derived more from hypothesis-generating experience than from concordant state-of-knowledge.

\section{Prevention of sepsis-induced AKI Fluid resuscitation \\ Aim}

The old "credo" stating that fluid harms the lung but benefits the kidney should be revised [10]. Liberal fluid administration is of key importance to optimize systemic hemodynamics in patients with SAKI. Yet, ongoing controversy exists about efficacy, nature, extent and duration of fluid therapy in septic shock [11]. In fact, ICU physicians are faced with a "double-edged" fluid dilemma. Volume resuscitation is indeed essential to restore and maintain cardiac output and oxygen delivery. Sustained or unrestricted infusion of fluids, however, will cause tissue edema which significantly contributes to organ dysfunction. On the other hand, too rapid or excessive fluid removal with diuretics or extracorporeal techniques may expose patients to severe hypovolemia and recurrent renal injury. An optimal fluid management would be to guarantee a stepwise and smooth transition from initial unrestricted fluid administration (positive fluid balance) over a state of equilibrium (steady-state fluid balance) to appropriate fluid removal (negative fluid balance) [12]. This process is kept on track by meticulous serial assessments of fluid handling aiming at welldefined cardiovascular and renal targets. Low intravascular oncotic pressure-the typical hallmark of patients with systemic inflammatory response syndrome (SIRS) and septic patients without AKI-is also observed in patients who develop SAKI $[13,14]$. This explains their particular vulnerability to potentially harmful fluid accumulation as compared with non-septic AKI patients [13]. Moreover, renal ischemia and reperfusion is associated with reduced capillary blood flow and loss of glycocalyx integrity [14]. Early aggressive fluid resuscitation can be life-saving [15], yet several observational studies in critically ill patients with SAKI have linked fluid overload to increased mortality and reduced kidney recovery [16, 17]. RRT may provide better control of fluid balance in this population. However, a mortality benefit of RRT is unproven and timing and dose remain matter of debate.

\section{Type of fluid}

Crystalloids versus colloids Hypotension and hypovolemia during sepsis may cause or worsen AKI. Evidence is accumulating suggesting that crystalloid but not colloid solutions should be used for initial intravascular volume expansion in septic patients at risk for AKI [18-20]. The substantial risk for induction of osmotic nephrosis (by pinocytosis in the renal tubules) strongly pleads against the use of hydroxyethyl starch and dextran solutions [1822].

Balanced crystalloids versus isotonic salt solutions Balanced crystalloid perfusions (e.g., Ringer's lactate, Plasmalyte $\left.{ }^{\circledR}\right)$ are associated with less occurrence of AKI than isotonic salt solutions [23]. The latter contain a too high chloride load which is thought to be detrimental for the kidney by inducing vasoconstriction in the renal vascular bed [23-25] and was independently associated with increased morbidity and mortality [22, 26]. Reported differences in incidence of AKI between patients receiving either buffered or saline crystalloids may also be influenced by unidentified confounding factors [27, 28]. Two recent retrospective trials in patients with sepsis [29] and SIRS [30] divulged an association between infusion of normal saline and increased in-hospital mortality. However, a recent large prospective randomized trial (Split Trial) reported no difference in AKI incidence in patients receiving either balanced crystalloids or isotonic salt solutions [31]. Thus, any suggested superiority of balanced crystalloids to isotonic saline for preventing SAKI remains to be proven.

\section{Albumin}

It is common belief that albumin solutions do force excess tissue water back into the endovascular space 
by creating a hyperoncotic effect. Surprisingly, this has never been evidenced [32]! Albumin infusion may even promote extracellular fluid overload without improving hypovolemia in sepsis complicating advanced cirrhosis or diabetes [33]. Any beneficial effect of albumin on patient outcome remains controversial. Data from the SAFE study [34] and a systematic review [35] showed that the use of albumin-containing solutions for the resuscitation of patients with sepsis was associated with lower mortality and did not impair renal function compared with other fluid resuscitation regimens. The recently published ALBIOS trial failed to show a mortality benefit in patients with severe sepsis who were fluid resuscitated with albumin and crystalloids as compared with crystalloids alone [36]. However, a post hoc analysis showed a significantly lower 90-day mortality in a subgroup of 1121 patients with septic shock treated with albumin [36]. Moreover, a recent review highlighted that ALBIOS patients who received albumin needed less vasopressive support and achieved a significantly better fluid balance [37]. Still, many uncertainties prevail as to the potential benefit, indications, and cost-effectiveness of albumin $[38,39]$.

\section{Early use of continuous RRT (CRRT)}

Fluid overload definitely increases kidney edema and enhances severity and irreversibility of SAKI [15-17]. Therefore, timely use of CRRT in case of fluid overload that is poorly responding or refractory to diuretics might be a reasonable approach to attenuate or control SAKI [40]. Weight gain at initiation of RRT has been associated with a poor outcome [41]. Awaiting further trials, the early use of CRRT is a reasonable yet not generally accepted approach to control fluid homeostasis.

\section{Monitoring \\ Electronic AKI "sniffers"}

Real-time electronic reporting systems have been developed to help recognizing AKI at an earlier stage [42] and to determine the eventual need for RRT $[43,44]$. An AKI alert is based on either RIFLE [42, 44] or AKIN [43] criteria. Ideally, AKI alert systems should be based on kidney improving global outcomes (KDIGO) criteria [45]. Although preliminary results were promising, a recent trial using these criteria did not confirm that early electronic detection of AKI improved outcome [46].

\section{Renal Doppler}

The kidneys receive approximately $25 \%$ of the total blood flow. Yet, they only use half of this flow mainly because of intricate intra-renal shunting [47]. Monitoring of global renal blood flow thus provides little information about the adequacy of oxygen supply to the kidneys [47]. As a consequence, renal Doppler is not a reliable tool to assess renal oxygen supply and its eventual response to fluid loading [48]. Future research rather should focus on the renal microcirculation. A pilot study of Schneider et al. used contrast-enhanced ultrasound (CEUS) to evaluate renal cortical perfusion in elective cardiac surgery patients. CEUS was feasible, well tolerated and results were reproducible. CEUS-derived parameters suggested a decrease in renal perfusion within $24 \mathrm{~h}$ of surgery [49] which persisted after correction of hemoglobin [49]. However, recently reported experience with CEUS was disappointing with regard to clinico-radiological correlation and reproducibility [50, 51]. In addition, CEUS may have questionable accuracy in the presence of important intra-renal and eventual peri-glomerular shunting [52].

\section{Central venous oxygen saturation $\left(\mathrm{S}_{\mathrm{cv}} \mathrm{O}_{2}\right)$ and lactate clearance rate}

$\mathrm{S}_{\text {cv }} \mathrm{O}_{2}$ Boosting systemic oxygen delivery under guidance of $\mathrm{S}_{\mathrm{cv}} \mathrm{O}_{2}$ has recently been shown to prevent or avoid progression of AKI but had no effect on mortality [53]. Recent studies, however, did not find a correlation between $\mathrm{S}_{\mathrm{cv}} \mathrm{O} 2$ values and AKI incidence [54]. Kidney performance is less influenced by enhanced oxygen delivery but strongly depends on adequate arterial perfusion pressure [55]. This explains why noradrenaline better preserves kidney function than dobutamine [56]. Setting higher $\mathrm{S}_{\mathrm{cv}} \mathrm{O}_{2}$ targets is an attractive approach for preventing SAKI [57] but more robust data regarding its feasibility and effectiveness in clinical practice are awaited.

Lactate clearance rate Lactate levels more appropriately reflect arterial perfusion than oxygen supply, especially when accounting for the high level of intra-renal oxygen shunting [47]. Lactate clearance rate could thus mirror kidney perfusion more adequately than $\mathrm{S}_{\mathrm{cv}} \mathrm{O}_{2}$ [47]. Lactate is a powerful predictor of mortality in patients with SAKI and improving lactate clearance has been associated with a better outcome [57]. Janssen et al. reported that lactate-guided therapy reduced the incidence of AKI in ICU patients [58]. In contrast, Jones et al. found that additional targeting of normal lactate levels as compared with aiming at higher $\mathrm{S}_{\mathrm{cv}} \mathrm{O}_{2}$ did not influence in-hospital mortality in septic shock patients resuscitated to normal central venous and mean arterial pressure (MAP) [59]. More outcome data from prospective lactate-driven resuscitation protocols are eagerly awaited.

\section{Central venous pressure (CVP) and kidney "afterload"}

For decades, clinicians estimated that preload was the main determinant of kidney function. Increasing preload was thought to increase renal blood volume and flow. Although a "critical" CVP level is required to ensure 
optimal renal function, unrestrained preload increase may harm the kidneys by enhancing venous congestion and blocking venous outflow (i.e., increased "afterload"). Recently, higher CVP levels were found to be associated with an increased incidence and morbidity of AKI during septic shock [54]. Relatively small increases in thoracic pressure already compromised venous return to the kidneys [54]. The kidneys are encapsulated and thus extremely vulnerable to compression by evolving edema. AKI due to such "kidney compartment syndrome" may be an early sign of abdominal hypertension [60]. CVP is a poor indicator of renal perfusion and, if used, serial readings are more useful than isolated values. An optimal CVP level is unknown but unrestrained "pumping up" of preload as protective measure for SAKI is obsolete [54, $55,60]$.

\section{Differentiating transient (functional) SAKI from structural SAKI}

\section{Urine biochemistry}

SAKI may present either as a functional or structural entity. The difference is clinically relevant since functional SAKI can be reversed completely by early adequate treatment whereas structural kidney damage will mostly require RRT. Discriminating functional from structural SAKI at the bedside, however, remains challenging. Low fractional excretions of sodium $\left(\mathrm{FE}_{\mathrm{Na}}\right)$ and urea $\left(\mathrm{FE}_{\mathrm{Urea}}\right)$ are highly prevalent during the initial phase of sepsis. Oliguria is an earlier sign of impending SAKI than the increase in serum creatinine. It is assumed that high $\mathrm{FE}_{\mathrm{Na}}$ and low $\mathrm{FE}_{\text {Urea }}$ values are associated with intrinsic SAKI whereas high values of both $\mathrm{FE}_{\mathrm{Na}}$ and $\mathrm{FE}_{\mathrm{Urea}}$ concur with transient or functional SAKI. However, a definite discriminative power of these urinary indices has not been established [61]. They are also less specific than currently tested biomarkers of SAKI [62] and less accurate for differentiating transient from persistent AKI [63] and SAKI from non-SAKI [64].

\section{Biomarkers}

Among various biomarker assays, neutrophil gelatinase-associated lipocalin, urine insulin-like growth factor-binding protein 7 , and tissue inhibitor of metalloproteinases- 2 are the most promising $[65,66]$. Still, these markers have limited availability and thus cannot be advocated for routine guidance of therapy. Bagshaw et al. prospectively showed that urinary sodium, $\mathrm{FE}_{\mathrm{Na}}$, and $\mathrm{FE}_{\text {Urea }}$ did not reliably predict biomarker release, worsening of AKI, need for RRT or mortality [64].

\section{Oliguria vs creatinine}

Oliguria is an earlier sign of impending SAKI than the increase in serum creatinine [61]. Macedo et al. reported that oliguric episodes occurred frequently in ICU patients and allowed to identify more AKI as compared to serum creatinine [67]. In contrast, other investigators found a poor specificity of oliguria [68, 69]. To date, no biological or laboratory marker can be put forward that reliably distinguishes functional from structural SAKI.

\section{Transfusion policy}

An optimal hematocrit level may contribute to SAKI prevention [70] but this is not supported by clinical data. A hematocrit value below $24 \%$ was associated with significantly more post-operative AKI in cardiac surgery patients with systemic inflammatory response syndrome who are known to display a sepsis-alike inflammatory state [71]. Whether a similar target should be pursued in patients with SAKI remains to be proven. A recent retrospective study showed that red blood cell (RBC) transfusion in non-bleeding critically ill patients with moderate anemia and without shock was associated with higher nosocomial infection rates, more AKI, and increased mortality [72]. This apparent "transfusion-related AKI" could be coined by the acronym "TRAKI" in analogy to "TRALI" which stands for "transfusion-related acute lung injury" $[72,73]$. As in TRALI, TRAKI may result from endothelial injury [74] as most of the protective glycocalyx layer above the endothelium is damaged and lost during severe sepsis [14]. Of note is that the introduction of citrate as an anticoagulant for CRRT resulted in significantly lower transfusion needs. A potential beneficial role of citrate in prevention and/or recovery of SAKI has been suggested [75] but needs confirmation. The FINNAKI study showed that the age of transfused RBCs was independently associated with in-hospital mortality but not 90-day mortality or KDIGO stage 3 AKI [76].

\section{Vasopressive and inotropic support}

As discussed earlier, a decreased renal blood flow and oxygen supply were wrongly assumed to be the main instigators of SAKI [8, 77]. This directed treatment towards increasing filling pressures (i.e., fluid administration) and/or cardiac output (i.e., inotropic support). In an experimental hypotensive and hyperdynamic septic shock model, Di Giantomasso et al. demonstrated that vasopression with noradrenaline significantly increased global and medullary renal blood flow and restored normal renal vascular tone [78]. In the same model, angiotensin II infusion decreased renal blood flow while markedly increasing diuresis and normalizing creatinine clearance [79]. Low-dose vasopressin did not reduce mortality rates as compared with noradrenaline among patients with septic shock [80]. In patients with SAKI, vasopressin only reduced progression to stage I but not to more severe AKI stages [81]. An optimal perfusion pressure 
has not yet been determined. Asfar et al. proposed (in a randomized controlled trial) a MAP of $65-70 \mathrm{mmHg}$ as reasonable objective [82] whilst another (observational) study found that MAP values between 72 and $82 \mathrm{mmHg}$ were necessary to prevent AKI in patients with septic shock and initially impaired renal function [83].

\section{Intra-abdominal hypertension}

Intra-abdominal hypertension (IAH) and its most dreaded presentation, the abdominal compartment syndrome (ACS), are frequently associated with AKI in surgical and trauma patients. Because signs and symptoms are non-specific and laboratory and imaging studies often remain inconclusive, the diagnosis of AKI as a manifestation of IAH requires a high index of clinical suspicion. Early recognition and treatment improve clinical outcome [84]. IAH has also been described in up to one-third of cardiac surgery patients where it was found to be strongly associated with higher baseline intra-abdominal pressure (IAP), increased CVP, positive fluid balance, extracorporeal circulation, use of vasoactive drugs and AKI. Determinants of IAH need accurate assessment and patients with any known risk factor(s) must be closely monitored during the perioperative period. In this context, the baseline IAP may be a valuable early warning parameter for IAH [85]. According to the most recent guidelines [86], IAP should be monitored in all surgical patients at risk for AKI (i.e., cardiac surgery, complicated abdominal surgery and post-operative sepsis) [84-86]. IAP is best measured with a bladder catheter. No consensus exists on whether AKI can be prevented by early abdominal decompression or administration of diuretics [84-86]. RRT may facilitate or improve volume management in some cases but cannot be recommended as standard treatment [84-86]. IAH and ACS also increase morbidity and mortality in medical ICU patients. Factors predisposing to $\mathrm{IAH} / \mathrm{ACS}$ in this population include sepsis, large-volume fluid resuscitation, polytransfusion, mechanical ventilation with high intrathoracic pressures, and acidosis.

\section{Treatment of sepsis-induced AKI}

\section{Dosing of CRRT}

High-volume hemofiltration offers no mortality benefit in SAKI $[6,87,88]$. Based on two large seminal trials with an important septic subpopulation $[89,90]$, a CRRT dose of $20-25 \mathrm{ml} / \mathrm{kg} / \mathrm{h}$ is currently issued by the KDIGO guidelines [45]. The prescribed dose should be somewhat higher to ascertain delivery of at least $20-25 \mathrm{ml} / \mathrm{kg} / \mathrm{h}$ [91]. A $25-30 \mathrm{ml} / \mathrm{kg} / \mathrm{h}$ dose may be more convenient in sepsis but no strong data support its recommendation [92].

\section{Timing of (C) RRT}

(C)RRT should be initiated when fluid overload is poorly tolerated and only partly or not responsive to a diuretic challenge [15]. The IVOIRE study demonstrated that starting CRRT at RIFLE injury level in established SAKI was associated with a very low 90-day mortality [87]. ICU patients requiring RRT, however, showed marked variation in factors that influence start of RRT. RRT initiation with fewer clinical triggers was associated with lower mortality [93]. In the recent observational study from the FINNAKI group, applying RRT for conventional indications at an early stage was also associated with lower mortality [94]. Timing of RRT may modify survival but awaits appraisal in three forthcoming randomized trials [95-97]. Meanwhile, it is acceptable to start CRRT at RIFLE injury/failure level as dictated by the KDIGO guidelines [45].

\section{Renal replacement modalities}

Prowle and Bellomo reported that hemodynamically unstable patients with SAKI treated with CRRT remained significantly less dialysis-dependent than those receiving intermittent hemodialysis (IHD) [98]. A recent meta-analysis by Schneider also suggested that CRRT outperformed IHD in obtaining renal recovery in patients without cardiovascular instability [99]. This meta-analysis is prone to criticism because many of the included studies are old, uncontrolled, or compare CRRT with inappropriately managed IHD [99]. Continuous veno-venous hemofiltration $(\mathrm{CVVH})$ was associated with a trend towards early reduction of vasopressor support [100]. To date, however, there are no strong decisive arguments to prefer CRRT or IHD as primary treatment for SAKI, except maybe in severely hemodynamically unstable patients (level 2B in the KDIGO guidelines) [45]. A large and sufficiently powered randomized trial comparing the effect of CRRT vs. IHD on renal recovery as primary endpoint would end this controversy.

\section{Diuretics}

The use of diuretics to induce or increase urine production in the absence of hypervolemia is associated with increased mortality [101] and should be discouraged. In contrast, diuretics might improve outcome when fluid balance remains positive or in case of overt fluid overload [102]. However, any beneficial effect of diuretics on mortality was lost after adjustment for fluid balance [102]. Ho and Power reviewed the use of furosemide in AKI and found no beneficial effects on mortality [103]. A furosemide stress test for early assessment of tubular function showed robust capacity to identify patients at risk for severe and progressive AKI [104] but needs validation in SAKI. 


\section{Antimicrobial dosing during CRRT}

CRRT significantly influences the pharmacokinetic and pharmacodynamic behavior of most antimicrobial agents. This is insufficiently anticipated by currently recommended dosing guidelines. Patients are particularly at risk for underdosing which may cause treatment failure and enhanced resistance. An in-depth discussion of antimicrobial handling during CRRT is beyond the scope of this review. Table 1 summarizes literature-based [105112] dose recommendations for some major antibiotic and antifungal drugs during $\mathrm{CVVH}$ at a dose of $25 \mathrm{ml} /$ $\mathrm{kg} / \mathrm{h}$. Colistin deserves special attention. Our group has shown that patients undergoing $\mathrm{CVVH}$ can support long-term colistin therapy at doses up to 4.5 million IU tid [108]. CVVH thus may act as a "shield" providing sufficiently high plasma colistin levels whilst avoiding toxicity [113]. Importantly, safe application of such treatment requires the use of filter membranes that allow high colistin adsorption in association with citrate anticoagulation to preserve optimal convective elimination capacity [114].

\section{Other blood purification strategies}

Several strategies are under investigation including newly designed membranes [114], apheresis or selective plasma exchange [115] and polymyxin B hemoperfusion [116]. These purification strategies fit in the

Table 1 Dose recommendations for some frequently used antimicrobials during CRRT, (CVVH mode; $25 \mathrm{ml} / \mathrm{kg} / \mathrm{h}$ )

\begin{tabular}{|c|c|c|}
\hline Antimicrobial & Loading dose & Maintenance dose \\
\hline Amikacin & $30-35 \mathrm{mg} / \mathrm{kg}$ & TDM \\
\hline Meropenem & $2 \mathrm{~g}$ & 2 g over $3 \mathrm{~h}$ tid \\
\hline Piperacillin-tazobactam & $4 \mathrm{~g} / 0.5 \mathrm{~g}$ & $16 \mathrm{~g} / 2 \mathrm{~g}(\mathrm{Cl})$ \\
\hline Vancomycin & 35 mg/kg over $4 \mathrm{~h}$ & $\begin{array}{l}30 \mathrm{mg} / \mathrm{kg} \\
\quad(\mathrm{TDM}=25-30 \mathrm{mg} / \mathrm{L})\end{array}$ \\
\hline Teicoplanin & $15 \mathrm{mg} / \mathrm{kg}$ bid & $600 \mathrm{mg} \mathrm{od}$ \\
\hline Linezolid & & $600 \mathrm{mg}$ tid \\
\hline Ciprofloxacin & $800 \mathrm{mg}$ & $400 \mathrm{mg}$ tid \\
\hline Tigecycline & $150 \mathrm{mg}$ & 100 mg bid \\
\hline Colistin & $9 \mathrm{MIU}$ & 4,5 MIU tid \\
\hline Voriconazole & $8 \mathrm{mg} / \mathrm{kg}$ bid & $6 \mathrm{mg} / \mathrm{kg}$ bid \\
\hline Fluconazole & & $600 \mathrm{mg}$ bid \\
\hline Cefepime & & $2 \mathrm{~g}$ tid \\
\hline Gentamycin & & $7 \mathrm{mg} / \mathrm{kg}$ od \\
\hline Bactrim & $\begin{array}{l}1200 \mathrm{mg} / 240 \mathrm{mg} \\
(3 \mathrm{amp})\end{array}$ & $\begin{array}{l}800 \mathrm{mg} / 160 \mathrm{mg} \\
(2 \mathrm{amp}) \mathrm{tid}\end{array}$ \\
\hline Clindamycin & & 900 mg qid \\
\hline
\end{tabular}

Adapted from references [105-113]

TDM therapeutic drug monitoring, od once daily, bid twice daily, tid three times daily, qid four times daily, amp ampules, $\mathrm{Cl}$ continuous infusion, MIU million units concept of host inflammatory response modulation, yet have not proven successful [117]. Hyperadsorptive membranes such as the acrylonitrile 69 surface-treated or polymethylmethacrylate filters very effectively adsorb crucial inflammatory mediators (e.g., high-mobility group box 1 protein (HMGB-1)) [118]. Although small-sized (26 kDa), HMGB-1 was not removed by convection but entirely by adsorption [118]. A preliminary study of polymyxin B hemoperfusion added to conventional therapy showed significantly improved hemodynamics, less organ dysfunction and reduced 28-day mortality in patients with severe sepsis and/or septic shock from abdominal origin [116]. However, a recently published multicenter randomized controlled study demonstrated a non-significant increase in mortality and no improvement in organ failure with polymyxin B hemoperfusion compared to conventional treatment of peritonitis-induced septic shock [119].

\section{Medical therapies}

A small randomized phase I trial showed that adjunctive treatment with recombinant alkaline phosphatase (RAP) could prevent SAKI and even reversed some cases of advanced SAKI [120]. A phase II clinical trial is currently ongoing [121]. The exact mechanism and optimal timing of action of RAP is still unclear. RAP probably combats renal inflammation through dephosphorylation of lipopolysaccharide and adenosine triphosphate [122, 123].

\section{Conclusions}

Prevention of SAKI starts with early and adequate fluid resuscitation. Crystalloids are preferred over colloids but balanced crystalloids do not appear superior to classic crystalloids for counteracting SAKI. Synthetic colloids and starches in particular should be withheld. No data support the use of albumin in patients with SAKI. Regarding SAKI prevention, $\mathrm{S}_{\mathrm{cv}} \mathrm{O}_{2}$ monitoring performs better than lactate clearance rate or renal Doppler for monitoring kidney perfusion. Lactate clearance rate, however, is better correlated with SAKI-related mortality. High filling pressures must be avoided in light of the detrimental effects imposed by an increased kidney "afterload". Noradrenaline remains the vasopressor of choice for preventing SAKI. Vasopressin or analogs need further investigation. IAH is a potential, yet often overlooked, trigger of SAKI. Early initiation of RRT is indicated when fluid overload is excessive or refractory to diuretics. CRRT is increasingly considered as first-choice therapy in hemodynamically unstable SAKI. Expanding its use to "stable" SAKI patients is attractive but not supported by current literature. Except for life-threatening 
hypervolemia, diuretics have no place in prevention or treatment of SAKI. Most antimicrobials require dose adaptation during CRRT.

\section{Authors' contributions}

PMH conceived, selected studies, and designed the review. PMH and HDS wrote the initial draft of the manuscript. PMH, RJ, IH, SMB, OJB, WB, EDW, VVG and HDS revised the manuscript. All authors have read and approved the final manuscript.

\section{Author details \\ ${ }^{1}$ Intensive Care Department, Universitair Ziekenhuis Brussel, Vrije Universiteit Brussel, Laarbeeklaan 101, 1090 Brussels, Belgium. ${ }^{2}$ Division of Critical Care Medicine, Faculty of Medicine and Dentistry, University of Alberta, Edmonton, AB, Canada. ${ }^{3}$ Haut Leveque University Hospital of Bordeaux, University of Bor- deaux 2, Pessac, France. ${ }^{4}$ Department of Anaesthesiology and Critical Care Medicine, Ziekenhuis Oost-Limburg, Genk, Belgium.}

\section{Acknowledgements}

SMB is supported by a Canada Research Chair in Critical Care Nephrology and a Clinical Investigator Award from Alberta Innovates-Health Solutions

\section{Competing interests}

PMH has received research grants from Gambro, Baxter, Bellco and Pfizer. SMB has received consultant and speaking fees for Gambro.

\section{Funding}

The study received no industry sponsorship.

Received: 16 July 2015 Accepted: 1 December 2015

Published online: 21 December 2015

\section{References}

1. Bagshaw SM, George C, Bellomo R, ANZICS Database Management Committee. Early acute kidney injury and sepsis: a multicentre evaluation. Crit Care. 2008;12:R47.

2. Uchino S, Kellum JA, Bellomo R, Doig GS, Morimatsu H, Morgera S, et al. Acute renal failure in critically ill patients: a multinational, multicenter study. JAMA. 2005;294:813-8.

3. Bagshaw SM, Uchino S, Bellomo R, Morimatsu H, Morgera S, Schetz M, Beginning and Ending Supportive Therapy for the kidney (BEST Kidney) Investigators, et al. Septic acute kidney injury in critically ill patients: clinical characteristics and outcomes. Clin J Am Soc Nephrol. 2007;2:431-9.

4. Poukkanen M, Vaara ST, Pettilä V, Kaukonen KM, Korhonen AM, Hovilehto $S$, et al. Acute kidney injury in patients with severe sepsis in Finnish Intensive Care Units. Acta Anaesthesiol Scand. 2013;57:863-72.

5. Gurjar M, Baronia AK, Azim A, Prasad N, Jain S, Singh RK, et al. Septic acute kidney injury in critically ill Indian patients. Indian J Crit Care Med. 2013;17:49-55.

6. Clark E, Molnar AO, Joannes-Boyau O, Honoré PM, Sikora L, Bagshaw SM. High-volume hemofiltration for septic acute kidney injury: a systematic review and meta-analysis. Crit Care. 2014;18:R7.

7. Angus DC, Linde-Zwirble WT, Lidicker J, Clermont G, Carcillo J, Pinsky MR. Epidemiology of severe sepsis in the United States: analysis of incidence, outcome, and associated costs of care. Crit Care Med. 2001;29:1303-10

8. Honore PM, Jacobs R, Joannes-Boyau O, De Regt J, Boer W, De Waele E, et al. Septic AKI in ICU patients. Diagnosis, pathophysiology, and treatment type, dosing, and timing: a comprehensive review of recent and future developments. Ann Intensive Care. 2011;1:32.

9. Gomez H, Ince C, De Backer D, Pickkers P, Payen D, Hotchkiss J, et al. A unified theory of sepsis-induced acute kidney injury: inflammation, microcirculatory dysfunction, bioenergetics, and the tubular cell adaptation to injury. Shock. 2014;41:3-11.

10. Prowle JR, Bellomo R. Fluid administration and the kidney. Curr Opin Crit Care. 2013;4:308-14.

11. Ia Puente-Diaz De, de Leon VM, Rivero-Sigarroa E, Domiguez-Cherit G, Namendys-Silva SA. Fluid therapy in severe sepsis and septic shock. Crit Care Med. 2013;41:484-5.
12. Goldstein SL. Fluid management in acute kidney injury. J Intensive Care Med. 2014;29:183-9.

13. Andreucci M, Federico S, Andreucci VE. Edema and acute renal failure. Semin Nephrol. 2001:21:251-6.

14. Snoeijs MG, Vink H, Voesten N, Christiaans MH, Daemen JW, Peppelenbosch AG, et al. Acute ischemic injury to the renal microvasculature in human kidney transplantation. Am J Physiol Renal Physiol. 2010;299:1134-40.

15. Prowle JR, Kirwan CJ, Bellomo R. Fluid management for the prevention and attenuation of acute kidney injury. Nat Rev Nephrol. 2014;10:37-47.

16. Bouchard J, Soroko SB, Chertow GM, Himmelfarb J, Ikizler TA, Paganin EP, Program to Improve Care in Acute Renal Disease (PICARD) Study Group, et al. Fluid accumulation, survival and recovery of kidney function in critically ill patients with acute kidney injury. Kidney Int. 2009;76:422-7.

17. Payen D, de Pont AC, Sakr Y, Spies C, Reinhart K, Vincent JL. Sepsis Occurrence in Acutely III Patients (SOAP) Investigators. A positive fluid balance is associated with a worse outcome in patients with acute renal failure. Crit Care. 2008;12:R74.

18. Mutter TC, Ruth CA, Dart AB. Hydroxyethyl starch (HES) versus other fluid therapies: effects on kidney function. Cochrane Database Syst Rev. 2013; 23.

19. Perner A, Haase N, Guttormsen AB, Tenhunen J, Klemenzson G, Åneman A, et al. Hydroxyethyl starch 130/0.42 versus Ringer's acetate in severe sepsis. N Engl J Med. 2012;367:124-34.

20. Myburgh JA, Finfer S, Bellomo R, Billot L, Cass A, Gattas D, et al. Hydroxyethyl starch or saline for fluid resuscitation in intensive care. N Engl J Med. 2012;367:1901-11.

21. Wiedermann CJ, Joannidis M. Accumulation of hydroxyethyl starch in human and animal tissues: a systematic review. Intensive Care Med. 2013; 21.

22. Shaw AD, Bagshaw SM, Goldstein SL, Scherer LA, Duan M, Schermer CR, et al. Major complications, mortality, and resource utilization after open abdominal surgery: $0.9 \%$ saline compared to Plasma-Lyte. Ann Surg. 2012;255:821-9.

23. Yunos NM, Bellomo R, Hegarty C, Story D, Ho L, Bailey M. Association between a chloride-liberal vs chloride-restrictive intravenous fluid administration strategy and kidney injury in critically ill adults. JAMA. 2012;308:1566-72.

24. Zhang Z, Xu X, Fan H, Li D, Deng H. Higher serum chloride concentrations are associated with acute kidney injury in unselected critically ill patients. BMC Nephrol. 2013;28(14):235.

25. Waikar SS, Winkelmayer WC. Saving the kidneys by sparing intravenous chloride? JAMA. 2012;308:1583-5.

26. McCluskey SA, Karkouti K, Wijeysundera D, Minkovich L, Tait G, Beattie WS. Hyperchloremia after noncardiac surgery is independently associated with increased morbidity and mortality: a propensity-matched cohort study. Anesth Analg. 2013;117:412-22.

27. Ince $\mathrm{C}$, Groeneveld $\mathrm{AB}$. The case for $0.9 \% \mathrm{NaCl}$ : is the undefendable, defensible? Kidney Int. 2014;86:1087-95.

28. Yunos NM, Bellomo R, Glassford N, Sutcliffe H, Lam Q, Bailey M. Chloride-liberal vs. chloride-restrictive intravenous fluid administration and acute kidney injury: an extended analysis. Intensive Care Med. 2015;41:257-64.

29. Raghunathan K, Shaw A, Nathanson B, Stürmer T, Brookhart A, Stefan MS, et al. Association between the choice of IV crystalloid and inhospital mortality among critically ill adults with sepsis. Crit Care Med. 2014:42:1585-91.

30. Shaw AD, Raghunathan K, Peyerl FW, Munson SH, Paluszkiewicz SM, Schermer CR. Association between intravenous chloride load during resuscitation and in-hospital mortality among patients with SIRS. Intensive Care Med. 2014;40:1897-905.

31. Young P, Bailey M, Beasley R, Henderson S, Mackle D, McArthur C, et al. Effect of a buffered crystalloid solution vs saline on acute kidney injury among patients in the intensive care unit: the SPLIT randomized clinical trial. JAMA. 2015;7:1-10.

32. Myburgh JA, Finfer S. Albumin is a blood product too-is it safe for all patients? Crit Care Resusc. 2009;11:67-70.

33. Kumar R, Kumar S, Lata S. Albumin infusion may deleteriously promote extracellular fluid overload without improving circulating hypovolemia in patients of advanced cirrhosis with diabetes mellitus and sepsis. Med Hypotheses. 2013;80:452-5. 
34. SAFE Study Investigators, Finfer S, McEvoy S, Bellomo R, McArthur C, Myburgh J, Norton R. Impact of albumin compared to saline on organ function and mortality of patients with severe sepsis. Intensive Care Med. 2011;37:86-96.

35. Delaney AP, Dan A, McCaffrey J, Finfer S. The role of albumin as a resuscitation fluid for patients with sepsis: a systematic review and meta-analysis. Crit Care Med. 2011;39:386-91.

36. Caironi P, Tognoni G, Masson S, Fumagalli R, Pesenti A, Romero M, ALBIOS Study Investigators, et al. Albumin replacement in patients with severe sepsis or septic shock. N Engl J Med. 2014;370:1412-21.

37. Wiedermann CJ, Joannidis M. Nephroprotective potential of human albumin infusion: a narrative review. Gastroenterol Res Pract. 2015;2015:912839.

38. Perel P, Roberts I, Ker K. Colloids versus crystalloids for fluid resuscitation in critically ill patients. Cochrane Database Syst Rev. 2013; 2:CD000567.

39. Patel A, Laffan MA, Waheed U, Brett SJ. Randomised trials of human albumin for adults with sepsis: systematic review and meta-analysis with trial sequential analysis of all-cause mortality. BMJ. 2014;22:349.

40. Fülöp T, Pathak MB, Schmidt DW, Lengvárszky Z, Juncos JP, Lebrun $\mathrm{CJ}$, et al. Volume-related weight gain and subsequent mortality in acute renal failure patients treated with continuous renal replacement therapy. ASAIO J. 2010;56:333-7.

41. Goldstein SL. Advances in pediatric renal replacement therapy for acute kidney injury. Semin Dial. 2011:2:187-91.

42. Colpaert K, Hoste EA, Steurbaut K, Benoit D, Van Hoecke S, De Turck F, et al. Impact of real-time electronic alerting of acute kidney injury on therapeutic intervention and progression of RIFLE class. Crit Care Med. 2012:40:1164-70.

43. Selby NM, Crowley L, Fluck RJ, McIntyre CW, Monaghan J, Lawson N, et al. Use of electronic results reporting to diagnose and monitor AKI in hospitalized patients. Clin J Am Soc Nephrol. 2012;7:533-40.

44. Goldstein SL, Kirkendall E, Nguyen H, Schaffzin JK, Bucuvalas J, Bracke $T$, et al. Electronic health record identification of nephrotoxin exposure and associated acute kidney injury. Pediatrics. 2013;132:756-67.

45. KDIGO AKI Work Group. KDIGO clinical practice guideline for acute kidney injury. Kidney Int (Suppl). 2012;17:1-138.

46. Wilson FP, Shashaty M, Testani J, Aqeel I, Borovskiy Y, Ellenberg SS, et al. Automated, electronic alerts for acute kidney injury; a single-blind, parallel-group randomised controlled trial. Lancet. 2015;385:1966-74.

47. Beierwaltes WH, Harrison-Bernard LM, Sullivan JC, Mattson DL. Assessment of renal function; clearance, the renal microcirculation, renal blood flow, and metabolic balance. Compr Physiol. 2013;3:165-200.

48. Dewitte A, Coquin J, Meyssignac B, Joannes-Boyau O, Fleureau C, Roze $\mathrm{H}$, et al. Doppler resistive index to reflect regulation of renal vascular tone during sepsis and acute kidney injury. Crit Care. 2012;16:R165

49. Schneider AG, Goodwin MD, Schelleman A, Bailey M, Johnson L, Bellomo R. Contrast-enhanced ultrasound to evaluate changes in renal cortical perfusion around cardiac surgery: a pilot study. Crit Care. 2013;17:R138.

50. Schneider AG, Goodwin MD, Schelleman A, Bailey M, Johnson L, Bellomo R. Contrast-enhanced ultrasonography to evaluate changes in renal cortical microcirculation induced by noradrenaline: a pilot study. Crit Care. 2014;18:653.

51. Schneider AG, Schelleman A, Goodwin MD, Bailey M, Eastwood GM, Bellomo R. Contrast-enhanced ultrasound evaluation of the renal microcirculation response to terlipressin in hepato-renal syndrome: a preliminary report. Ren Fail. 2015;37:175-9.

52. Verma SK, Molitoris BA. Renal endothelial injury and microvascular dysfunction in acute kidney injury. Semin Nephrol. 2015;35:96-107.

53. Raimundo $M$, Crichton $S$, Syed $Y$, Martin JR, Beale $R$, Treacher $D$, et al. Low systemic oxygen delivery and bp and risk of progression of early AKI. Clin J Am Soc Nephrol. 2015;10:1340-9.

54. Legrand M, Dupuis C, Simon C, Gayat E, Mateo J, Lukaszewicz AC, et al. Association between systemic hemodynamics and septic acute kidney injury in critically ill patients: a retrospective observational study. Crit Care. 2013:17:R278.

55. Wong BT, Chan MJ, Glassford NJ, Mårtensson J, Bion V, Chai SY et al. Mean arterial pressure and mean perfusion pressure deficit in septic acute kidney injury. J Crit Care. 2015.

56. Bellomo R, Wan L, May C. Vasoactive drugs and acute kidney injury. Crit Care Med. 2008:36:179-86.
57. Chertoff J, Chisum M, Garcia B, Lascano J. Lactate kinetics in sepsis and septic shock: a review of the literature and rationale for further research. J Intensive Care. 2015;3:39.

58. Jansen TC, van Bommel J, Schoonderbeek FJ, Sleeswijk Visser SJ, van der Klooster JM, LACTATE study group. Early lactate-guided therapy in intensive care unit patients: a multicenter, open-label, randomized controlled trial. Am J Respir Crit Care Med. 2010;182:752-61.

59. Jones AE, Shapiro NI, Trzeciak S, Arnold RC, Claremont HA, Kline JA, Emergency Medicine Shock Research Network (EMShockNet) Investigators. Lactate clearance vs central venous oxygen saturation as goals of early sepsis therapy: a randomized clinical trial. JAMA. 2010;303:739-46.

60. Sandhu G, Mankal P, Gupta I, Ranade A, Bansal A, Jones J. Pathophysiology and management of acute kidney injury in the setting of abdominal compartment syndrome. Am J Ther. 2012.

61. Vanmassenhove J, Glorieux G, Hoste E, Dhondt A, Vanholder R, Van Biesen W. Urinary output and fractional excretion of sodium and urea as indicators of transient versus intrinsic acute kidney injury during early sepsis. Crit Care. 2013;17:R 234.

62. Honoré PM, Jacobs R, Joannes-Boyau O, Boer W, De Waele E, Van Gorp $V$, et al. Fractional excretion of urea to differentiate transient from persistent acute kidney injury: should we still trust old tools in the biomarker era? J Crit Care. 2012;27:514-5.

63. Pons B, Lautrette A, Oziel J, Dellamonica J, Vermesch R, Ezingeard E, et al. Diagnostic accuracy of early urinary index changes in differentiating transient from persistent acute kidney injury in critically ill patients: multicenter cohort study. Crit Care. 2013;17:R56.

64. Bagshaw SM, Bennett M, Devarajan P, Bellomo R. Urine biochemistry in septic and non-septic acute kidney injury: a prospective observational study. J Crit Care. 2013;28:371-8.

65. Honore PM, Jacobs R, Joannes-Boyau O, Verfaillie L, De Regt J, Van Gorp $V$, et al. Biomarkers for early diagnosis of AKI in the ICU: ready for prime time use at the bedside? Ann Intensive Care. 2012;2:R24.

66. Kashani K, Al-Khafaji A, Ardiles T, Artigas A, Bagshaw SM, Bell M, et a Discovery and validation of cell cycle arrest biomarkers in human acute kidney injury. Crit Care. 2013;17: R 25.

67. Macedo E, Malhotra R, Claure-Del Granado R, Fedullo P, Mehta RL. Defining urine output criterion for acute kidney injury in critically ill patients. Nephrol Dial Transplant. 2011;26:509-15.

68. Legrand M, Jacquemod A, Gayat E, Collet C, Giraudeaux V, Launay JM, et al. Failure of renal biomarkers to predict worsening renal function in high-risk patients presenting with oliguria. Intensive Care Med. 2015:41:68-76.

69. Prowle JR, Liu YL, Licari E, Bagshaw SM, Egi M, Haase M, et al. Oliguria as predictive biomarker of acute kidney injury in critically ill patients. Crit Care. 2011;15:R172.

70. Konrad FM, Mik EG, Bodmer SI, Ates NB, Willems HF, Klingel K, et al. Acute normovolemic hemodilution in the pig is associated with renal tissue edema, impaired renal microvascular oxygenation, and functional loss. Anesthesiology. 2013;119:256-69.

71. Swaminathan M, Phillips-Bute BG, Conlon PJ, Smith PK, Newman MF, Stafford-Smith M. The association of lowest hematocrit during cardiopulmonary bypass with acute renal injury after coronary artery bypass surgery. Ann Thorac Surg. 2003:76:784-91.

72. Leal-Noval SR, Muñoz-Gómez M, Jiménez-Sánchez M, Cayuela A, LealRomero M, Puppo-Moreno A, et al. Red blood cell transfusion in nonbleeding critically ill patients with moderate anemia: is there a benefit? Intensive Care Med. 2013;39:445-53.

73. Jaworski K, Maślanka K, Kosior DA. Transfusion-related acute lung injury: a dangerous and underdiagnosed non cardiogenic pulmonary edema. Cardiol J. 2013;20:337-44.

74. Sayah DM, Looney MR, Toy P. Transfusion reactions: newer concepts on the pathophysiology, incidence, treatment, and prevention of transfusion-related acute lung injury. Crit Care Clin. 2012;28:363-72.

75. Oudemans-van Straaten HM, Bosman RJ, Koopmans M, van der Voort $\mathrm{PH}$, Wester JP, van der Spoel JI, et al. Citrate anticoagulation for continuous venovenous hemofiltration. Crit Care Med. 2009:37:545-52.

76. Kaukonen KM, Vaara ST, Pettilä V, Bellomo R, Tuimala J, Cooper DJ, The FINNAKI study group, et al. Age of red blood cells and outcome in acute kidney injury. Crit Care. 2013:17:R222.

77. Schrier RW, Wang W. Acute renal failure and sepsis. N Engl J Med. 2004:351:159-69 (Review). 
78. Di Giantomasso D, Morimatsu H, May CN, Bellomo R. Intrarenal blood flow distribution in hyperdynamic septic shock: effect of norepinephrine. Crit Care Med. 2003;31:2509-13.

79. Wan L, Langenberg C, Bellomo R, May CN. Angiotensin II in experimental hyperdynamic sepsis. Crit Care. 2009;13:R190.

80. Russell JA, Walley KR, Singer J, Gordon AC, Hébert PC, Cooper DJ, et al. Vasopressin versus norepinephrine infusion in patients with septic shock. N Engl J Med. 2008;358:877-87.

81. Gordon AC, Russell JA, Walley KR, Singer J, Ayers D, Storms MM, et al. The effects of vasopressin on acute kidney injury in septic shock. Intensive Care Med. 2010;36:83-91.

82. Asfar P, Meziani F, Hamel JF, Grelon F, Megarbane B, Anguel N, et al. High versus low blood-pressure target in patients with septic shock. N Engl J Med. 2014;370:1583-93.

83. Badin J, Boulain T, Ehrmann S, Skarzynski M, Bretagnol A, Buret J, et al. Relation between mean arterial pressure and renal function in the early phase of shock: a prospective, explorative cohort study. Crit Care. 2011;15:R135

84. Dalfino L, Sicolo A, Paparella D, Mongelli M, Rubino G, Brienza N. Intraabdominal hypertension in cardiac surgery. Interact CardioVasc Thorac Surg. 2013;17:644-51.

85. Mohmand H, Goldfarb S. Renal dysfunction associated with intraabdominal hypertension and the abdominal compartment syndrome. J Am Soc Nephrol. 2011:4:615-21.

86. Kirkpatrick AW, Roberts DJ, De Waele J, Jaeschke R, Malbrain ML, De Keulenaer B, et al. Pediatric Guidelines Sub-Committee for the World Society of the Abdominal Compartment Syndrome. Intra-abdominal hypertension and the abdominal compartment syndrome: updated consensus definitions and clinical practice guidelines from the World Society of the Abdominal Compartment Syndrome. Intensive Care Med. 2013;39:1190-206.

87. Joannes-Boyau O, Honoré PM, Perez P, Bagshaw SM, Grand H, Canivet $J$, et al. High-volume versus standard-volume haemofiltration for septic shock patients with acute kidney injury (IVOIRE study): a multicentre randomized controlled trial. Intensive Care Med. 2013;39:1535-46.

88. Zhang P, Yang Y, LV R, Zhang Y, Xie W, Chen J. Effect of the intensity of continuous renal replacement therapy in patients with sepsis and acute kidney injury: a single-center randomized clinical trial. Nephrol Dial Transplant. 2012;27:967-73.

89. VA/NIH Acute Renal Failure Trial Network, Palevsky PM, Zhang JH, O'Connor TZ, Chertow GM, Crowley ST, Choudhury D, et al. Intensity of renal support in critically ill patients with acute kidney injury. N Engl J Med. 2008;359:7-20.

90. RENAL Replacement Therapy Study Investigators, Bellomo R, Cass A, Cole L, Finfer S, Gallagher M, Lo S, et al. Intensity of continuous renal-replacement therapy in critically ill patients. N Engl J Med. 2009;361:1627-38.

91. Vesconi S, CruzDN, Fumagalli R, Kindgen-Milles D, Monti G, Marinho A, DOse REsponse Multicentre International collaborative Initiative (DO-RE-MI Study Group), et al. Delivered dose of renal replacement therapy and mortality in critically ill patients with acute kidney injury. Crit Care. 2009;13:R57.

92. Joannidis M. Why did dose trials fail? Contrib Nephrol. 2011;174:222-31.

93. Bagshaw SM, Wald R, Barton J, Burns KE, Friedrich JO, House AA, et al. Clinical factors associated with initiation of renal replacement therapy in critically ill patients with acute kidney injury-a prospective multicenter observational study. J Crit Care. 2012;27:268-75.

94. Vaara ST, Reinikainen M, Wald R, Bagshaw SM, Pettilä V, FINNAKI Study Group. Timing of RRT based on the presence of conventional indications. Clin J Am Soc Nephrol. 2014;9:1577-85.

95. Wald R, Adhikari NK, Smith OM, Weir MA, Pope K, Cohen A, et al. Comparison of standard and accelerated initiation of renal replacement therapy in acute kidney injury. Kidney Int. 2015;88:897-904.

96. Barbar SD, Binquet C, Monchi M, Bruyere R, Quenot JP. Impact on mortality of the timing of renal replacement therapy in patients with severe acute kidney injury in septic shock: the IDEAL-ICU study (initiation of dialysis early versus delayed in the intensive care unit): study protocol for a randomized controlled trial. Trials. 2014;15:270.

97. Gaudry S, Hajage D, Schortgen F, Martin-Lefevre L, Tubach F, Pons B, et al. Comparison of two strategies for initiating renal replacement therapy in the intensive care unit: study protocol for a randomized controlled trial (AKIKI). Trials. 2015;16:170.
98. Prowle JR, Bellomo R. Continuous renal replacement therapy: recent advances and future research. Nat Rev Nephrol. 2010;6:521-9.

99. Schneider AG, Bellomo R, Bagshaw SM, Glassford NJ, Lo S, Jun M, et al. Choice of renal replacement therapy modality and dialysis dependence after acute kidney injury: a systematic review and meta-analysis. Intensive Care Med. 2013:39:987-97.

100. Wald R, Friedrich JO, Bagshaw SM, Burns KE, Garg AX, Hladunewich MA, et al. Optimal Mode of clearance in critically ill patients with Acute Kidney Injury (OMAKI) — a pilot randomized controlled trial of hemofiltration versus hemodialysis: a Canadian Critical Care Trials Group project. Crit Care. 2012;16:R205.

101. Mehta RL, Pascual MT, Soroko S, Chertow GM, PICARD Study Group. Diuretics, mortality, and nonrecovery of renal function in acute renal failure. JAMA. 2002;288:2547-53.

102. Grams ME, Estrella MM, Coresh J, Brower RG, Liu KD, National Heart, Lung, and Blood Institute Acute Respiratory Distress Syndrome Network. Fluid balance, diuretic use, and mortality in acute kidney injury. Clin J Am Soc Nephrol. 2011;6:966-73.

103. Ho KM, Power BM. Benefits and risks of furosemide in acute kidney injury. Anaesthesia. 2010;65:283-93.

104. Chawla LS, Davison DL, Brasha-Mitchell E, Koyner JL, Arthur JM, Shaw $A D$, et al. Development and standardization of a furosemide stress test to predict the severity of acute kidney injury. Crit Care. 2013;17:R 207.

105. Taccone FS, de Backer D, Laterre PF, Spapen H, Dugernier T, Delattre I, et al. Pharmacokinetics of a loading dose of amikacin in septic patients undergoing continuous renal replacement therapy. Int J Antimicrob Agents. 2011;37:531-5.

106. de Montmollin E, Bouadma L, Gault N, Mourvillier B, Mariotte E, Chemam $\mathrm{S}$, et al. Predictors of insufficient amikacin peak concentration in critically ill patients receiving a $25 \mathrm{mg} / \mathrm{kg}$ total body weight regimen. Intensive Care Med. 2014;40:998-1005.

107. Beumier M, Roberts JA, Kabtouri H, Hites M, Cotton F, Wolff F, et al. A new regimen for continuous infusion of vancomycin during continuous renal replacement therapy. J Antimicrob Chemother. 2013;68:2859-65.

108. Honoré PM, Jacobs R, Joannes-Boyau O, Lochy S, Boer W, De Waele E, et al. Continuous renal replacement therapy-related strategies to avoid colistin toxicity: a clinically orientated review. Blood Purif. 2014;37:291-5.

109. Breilh D, Jacobs $R$, Honoré PM, Dewitte A, Rozé H, Perez P et al: IVOIRE study group. Pharmacokinetics and Pharmacodynamics of anti-infective agents during continuous veno-venous hemofiltration in critically ill patients: an IVOIRE sub-study. To be submitted 2015.

110. Honore PM, Jacobs R, Hendrickx I, De Waele E, Van Gorp V, Spapen HD. Meropenem therapy in extracorporeal membrane oxygenation patients: an ongoing pharmacokinetic challenge. Crit Care. 2015;19:263.

111. Boselli E, Breilh D, Rimmelé T, Guillaume C, Xuereb F, Saux MC, et al. Alveolar concentrations of piperacillin/tazobactam administered in continuous infusion to patients with ventilator-associated pneumonia. Crit Care Med. 2008;36:1500-6.

112. Honore PM, Jacobs R, Hendrickx I, De Waele E, Van Gorp V, Spapen HD. Continuous renal replacement therapy for safe and adequate voriconazole intravenous treatment: enough reason to be confident? Crit Care. 2015;19:234.

113. Honore PM, Jacobs R, Lochy S, De Waele E, Van Gorp V, De Regt J, et al. Acute respiratory muscle weakness and apnea in a critically ill patient induced by colistin neurotoxicity: key potential role of hemoadsorption elimination during continuous veno venous hemofiltration. Int J Nephrol Renovasc Dis. 2013:6:107-11.

114. Honore PM, Jacobs R, Joannes-Boyau O, De Regt J, De Waele E, van Gorp V, et al. Newly designed CRRT membranes for sepsis and SIRS-a pragmatic approach for bedside intensivists summarizing the more recent advances: a systematic structured review. ASAIO J. 2013;59:99-106.

115. Stegmayr B, Abdel-Rahman EM, Balogun RA. Septic shock with multiorgan failure: from conventional apheresis to adsorption therapies. Semin Dial. 2012;25:171-5.

116. Cruz DN, Antonelli M, Fumagalli R, Foltran F, Brienza N, Donati A, et al. Early use of polymyxin B hemoperfusion in abdominal septic shock: the EUPHAS randomized controlled trial. JAMA. 2009:301:2445-52.

117. Honore PM, Joannes-Boyau O, Boer W, Gressens B. High Volume haemofiltration and hybrid techniques in sepsis: new insights into the rationale. Neth J Crit Care. 2007;11:239-42. 
118. Yumoto M, Nishida O, Moriyama K, Shimomura Y, Nakamura T, Kuriyama $\mathrm{N}$, et al. In vitro evaluation of high mobility group box 1 protein removal with various membranes for continuous hemofiltration. Ther Apher Dial. 2011;15:385-93.

119. Payen DM, Guilhot J, Launey Y, Lukaszewicz AC, Kaaki M, Veber B, et al. Early use of polymyxin B hemoperfusion in patients with septic shock due to peritonitis: a multicenter randomized control trial. Intensive Care Med. 2015;41:975-84.

120. Pickkers P, Heemskerk S, Schouten J, Laterre PF, Vincent JL, Beishuizen A, et al. Alkaline phosphatase for treatment of sepsis-induced acute kidney injury: a prospective randomized double-blind placebo-controlled trial. Crit Care. 2012;16:R14.
121. Peters E, Masereeuw R, Pickkers P. The potential of alkaline phosphatase as a treatment for sepsis-associated acute kidney injury. Nephron Clin Pract. 2014;127:144-8.

122. Peters $E_{1}$ Heemskerk S, Masereeuw R, Pickkers P. Alkaline phosphatase: a possible treatment for sepsis-associated acute kidney injury in critically ill patients. Am J Kidney Dis. 2014;13:1636-43.

123. Peters E, Geraci S, Heemskerk S, Wilmer MJ, Bilos A, Kraenzlin B et al. Alkaline phosphatase protects against renal inflammation through dephosphorylation of lipopolysaccharide and adenosine triphosphate. Br J Pharmacol. 2015.

\section{Submit your manuscript to a SpringerOpen ${ }^{\odot}$ journal and benefit from:}

- Convenient online submission

- Rigorous peer review

- Immediate publication on acceptance

- Open access: articles freely available online

- High visibility within the field

- Retaining the copyright to your article

Submit your next manuscript at $>$ springeropen.com 